\title{
CT Findings in Patients with Esophageal Carcinoma and Its Correlation with Esophagographic Findings
}

\author{
Basudev Agrawal \\ Department of Radiology, Govt. Medical College and Rajindra Hospital, Patiala, India \\ Email: dr.basudevagrawal@gmail.com
}

How to cite this paper: Agrawal, B. (2018) CT Findings in Patients with Esophageal Carcinoma and Its Correlation with Esophagographic Findings. Open Journal of Radiology, 8, 109-124. https://doi.org/10.4236/ojrad.2018.82013

Received: April 9, 2018

Accepted: June 24, 2018

Published: June 27, 2018

Copyright $\odot 2018$ by author and Scientific Research Publishing Inc. This work is licensed under the Creative Commons Attribution International License (CC BY 4.0).

http://creativecommons.org/licenses/by/4.0/

\section{(c) (i) Open Access}

\begin{abstract}
Aim of the Study: Aim of this study is to evaluate the patients of biopsy proven esophageal carcinoma with Contrast CT studies (CECT thorax, abdomen or neck), correlate and compare the CT findings with esophagographic findings in each case and with biopsy findings wherever possible. Materials and Methods: Fifty (50) biopsy proven cases of esophageal carcinoma were taken into study in Radiology Department of Govt. Medical College, Patiala, Punjab after informed consents. All the patients underwent esophagography with barium sulphate as the contrast material and contrast enhanced CT scan of neck and/or thorax and/or abdomen. In all cases, esophagographic study preceded the CT scan. The time gap between the two studies was kept to the minimum to make the studies comparable. Results: The CT findings were found to have significant correlation with the esophagographic findings ( $\mathrm{p}$ value $>0.05$ in each finding) in regard to luminal narrowing, proximal dilatation and hold up of contrast, eccentricity of growth, site involved, length of growth, involvement of pyriform sinuses/valeculla and involvement of GE junction. Conclusions: CT study primarily helps to rule out unresectable or distant metastatic disease. Barium studies cannot provide any information regarding local invasion into mediastinal structures, regional or non-regional lymphadenopathy or metastases to distant organs which are significant for determining the treatment modality. CT has an advantage over esophagography for these information.
\end{abstract}

\section{Keywords}

Esophageal Carcinoma, Esophagography, CT, Correlation

\section{Introduction}

The prevalent histology of esophageal tumors is Squamous cell carcinoma in 
most parts of the world [1]. More than $90 \%$ of esophageal cancers are either Squamous cell carcinoma (SCCs) or Adenocarcinoma [2]. Other histological types like small cell carcinoma (oat cell carcinoma) are extremely rare. Non-regional lymph nodes metastases are designated as M1a disease because patients with M1a disease have a worse prognosis than those with N1 disease [3]. In general, intra-thoracic and abdominal lymph nodes greater than $1 \mathrm{~cm}$ in diameter are considered to be enlarged, and supraclavicular lymph nodes with a short axis greater than $5 \mathrm{~mm}$ are considered to be pathologic [4] [5].

\section{Regional Lymph Nodes in Esophageal Cancer [6]}

1) Cervical esophagus

Scalene, Internal jugular, Upper and lower cervical, Periesophageal, Supraclavicular

2) Intra-thoracic esophagus (upper, middle and lower)

Upper periesophageal (above the azygos vein)-Subcarinal

Lower periesophageal (below the azygos vein)

3) Gastro-esophageal junction

Lower esophageal (below the azygos vein), Diaphragmatic, Pericardial,

Left gastric, Celiac.

Non-regional lymph nodes include cervical lymph nodes (for proximal esophageal tumors) and celiac axis lymph nodes (for distal esophageal tumors). Celiac lymph nodes are considered to be regional lymph nodes if the tumor involves gastro-esophageal junction. The sensitivity of spiral CT for the detection of masses $1 \mathrm{~cm}$ or larger is approximately $90 \%$ [7].

Barium studies are often used to evaluate these patients and double contrast barium studies have been found to be a sensitive technique for detection of carcinoma esophagus and esophagogastric junction with a positive predictive value of $42 \%$ [8]. When an esophageal stricture is identified by esophagography, it may be classified as benign or malignant. Benign strictures typically have symmetric areas of narrowing with smooth contour and tapered proximal and distal margins. Malignant strictures typically cause asymmetric narrowing with abrupt, shelf like margins and irregular contours with a nodular or ulcerated mucosal surface [9]. Esophageal tumors can be polypoidal, infiltrative, varicoid or ulcerative when seen by esophagography [10]. Superficial spreading lesions tend to show a nodular mucosal pattern without a well-defined mass. Early esophageal cancers may have very subtle findings on barium studies and therefore endoscopic follow-up of any suspected abnormality should be performed [9] [10]. In depressed lesions, the presence and size of mucosal surface granules were found to correlate with the depth of invasion, as did thickened folds and esophageal wall rigidity [11] [12]. Gastric invasion is an unusual finding with Squamous cell carcinoma, which largely occur in the middle third of esophagus [13]. Complications such as tracheo-esophageal fistula formation from a locally advanced disease can be seen on barium studies. Once a diagnosis of esophageal malignancy has been established, barium studies may be used to evaluate the morphology and size of tumors before and after treatment. Esophageal cancer can 
easily spread to adjacent structures in the neck or thorax, including the trachea, thyroid gland, larynx, bronchi, aorta, lung, pericardium, and diaphragm [14]. Tracheo-bronchial invasion may result in tracheo-esophageal or broncho-esophageal fistulas [15]. It may be difficult to determine whether two discrete lesions represent synchronous primary tumors or a single cancer with disseminated lymphatic metastases [13]. The most common sites of metastases includes the liver, lungs, bones, adrenal glands, kidneys, and brain, in descending order of frequency of occurrence [16] [17].

Computed tomography (CT) is considered complimentary to endoscopy and barium studies and is used to stage and follow esophageal cancers. CT can be used to define the local extent of tumor by showing the extent of involvement of esophageal wall by tumor and tumor invasion of periesophageal fat. CT cannot reliably delineate the individual layers of the esophageal wall and therefore cannot distinguish between $\mathrm{T} 1$ and $\mathrm{T} 2$ lesions. Infiltration of the tumor into the periesophageal fat as seen on CT denotes a T3 tumor and does adversely affect prognosis, although en-bloc resection for cure may still be attempted [18]. The reported accuracy of CT in diagnosing mediastinal invasion ranges from $59 \%$ to $82 \%$ [18]. Tumor infiltration to involve adjacent mediastinal structures such as the aorta or tracheo-bronchial tree denotes a T4 lesion that is considered inoperable. Contiguous invasion of adjacent structures may be difficult to predict when tumor abuts other structures in the mediastinum. Specific findings of tracheo-bronchial invasion include demonstration of a tracheo-bronchial fistula or tumor extension within the airway lumen. If the esophageal tumor indents or displaces the adjacent airway, invasion is likely. Thickening of the wall of tracheo-bronchial tree also suggests invasion. Loss of fat planes between the tumor and the adjacent airway is not always a specific finding for tumor invasion and may be seen in normal individuals; however, if the loss of fat planes occurs only at the level of esophageal mass with preservation of fat planes cranially and caudally, invasion is likely. Virtual endoscopy has been attempted to determine its value in patients with esophageal cancer infiltrating the tracheo-bronchial tree and found to be accurate in identifying endoluminal tumors in those patients who were not amenable to endoscopy although it could not be used to replace endoscopy in all patients with tracheo-bronchial invasion [19]. The overall circumference of contact between tumor and the aortic wall was shown to be a useful predictor with an interference arc greater than 90 degrees suggesting invasion [20]. The loss of the triangular area of fat between the esophagus, aorta and spine has also been used to predict aortic invasion [21]. The normal esophageal wall is usually less than $3 \mathrm{~mm}$ thick at CT when the esophagus is distended [22]; any wall thickness greater than $5 \mathrm{~mm}$ is considered abnormal [23]. $\mathrm{CT}$ is unable to adequately help differentiate between $\mathrm{T} 1, \mathrm{~T} 2$ and $\mathrm{T} 3$ disease, a distinction that is important when considering the use of neo-adjuvant chemotherapy and radiation therapy [24]. Exclusion of T4 disease, as indicated by the preservation of fat planes between the esophageal cancer and the adjacent structures, is the most important role of CT in the determination of $\mathrm{T}$ status [25]. 
Displacement of the trachea or bronchus, or indentation of the posterior wall of the trachea or bronchus by the tumor, have also proved accurate in predicting tracheo-bronchial invasion [26]. Pericardial invasion is suspected if pericardial thickening, pericardial effusion, or indentation of the heart with loss of the pericardial fat plane is seen. The reported sensitivity and specificity of CT for detecting mediastinal invasion in patients with esophageal cancer are $88 \%$ to $100 \%$ and $85 \%$ to $100 \%$ respectively [27]. Although obliteration of fat planes is a reliable sign of tumor involvement of adjacent structures, it can also occur in cachectic patients or in patients who have undergone radiation therapy or surgery [27].

\section{Material and Methods}

The study was carried out in the Department of Radio-diagnosis, Rajindra Hospital, Patiala, Punjab (India) during December 2010 to June 2012. Fifty (50) biopsy proven patients of esophageal carcinoma were included in the study after informed consent. All the patients underwent esophagography with barium sulphate as the contrast material and contrast enhanced CT scan of neck and/or thorax and/or abdomen. In all the cases, esophagographic study preceded the CT scan. The time gap between the two studies was kept to the minimum to make the studies comparable.

Patients were scanned using Siemens 6 slice Somatom Emotion Machine. Soft copy images were studied and analyzed on the high resolution radiology monitor. Hard copy was available for the patient referral. The details of the procedure were explained to the patient. Serial CT slices were obtained at a distance of every $8 \mathrm{~mm}$. Axial images were taken of the body part (neck, thorax or abdomen) under study. Coronal and sagittal reconstructions were done whenever needed. Each study was done with straight gantry. Slice thickness of $8 \mathrm{~mm}$ with $8 \mathrm{~mm}$ collimation was used. Very uncooperative patients were studied after giving mild sedation to the patient. Documentation was done with a window width of 300 for non-enhanced (NE) CT and 350 for contrast enhanced CT (CECT). The window centre selected was $30-50$ for NECT and CECT. Bone windows for possible bony involvement i.e. W2300/C-250 and lung window for possible parenchymal or pleural involvement were obtained in all relevant cases $(\mathrm{W}=1600$, $\mathrm{C}=-600)$.

Non-ionic contrast (Ioversol) was used in our study. Contrast was injected intravenously by the peripheral intravenous route. Continuous monitoring of the vital parameters and allergic reactions (if any) was done during contrast injection. Oral contrast was given in all cases.

Single contrast esophagographic studies were done on $500 \mathrm{~mA}$ X-ray machine of Allangers. Barium sulphate solution was used as contrast material in these studies which was prepared by diluting the Barium sulphate powder with water in a ratio of 1:1 dilution.

Patients were advised to come in the morning time with overnight fasting in order to prevent aspiration during the procedure. The procedure was well explained to the patient before starting it. All the studies were done with the pa- 
tient in the standing position. Additional images were taken in supine and prone position whenever required and in patients who were too sick to undergo the procedure in standing position. All the patients who aspirated significant amount of contrast material and thus could not underwent further study were excluded from the study. Patients with slight or minimal aspiration of contrast who were able to undergo complete study were included in the study. Lateral and Antero-posterior views were taken as images including the whole length of esophagus up to the gastroesophageal junction. Additional oblique views were taken whenever required.

\section{Results}

29 patients were males and 21 patients were females among 50 patients studied, showing a slight male predominance with M: F ratio of 1.38:1. Age distribution were as follows-below 35 years-3 (6\%), 35 - 45 years-6 (12\%), 45 - 55 years-10 (20\%), 55 - 65 years-19 (38\%), above 65 years-12 (24\%). Most common age group affected was 55 - 65 years of age followed by above 65 years of age, which suggests that esophageal carcinoma is more commonly seen in elderly. Most common presenting complaint was dysphagia (100\%) followed by weight loss (52\%) ,and chest/epigastric pain (18\%). Only 10\% patients presented with cough and vomiting, $8 \%$ with odynophagia, $4 \%$ with complaint of hoarseness of voice and $8 \%$ with other complaints like GI bleed, hiccups etc. The most common histological type was Squamous cell carcinoma (94\%) followed by Adenocarcinoma (6\%). The lower $1 / 3^{\text {rd }}$ of the esophagus including the GE junction was the most common site (46\%) followed by middle $1 / 3^{\text {rd }}$ of the esophagus (40\%). The upper $1 / 3^{\text {rd }}$ of the esophagus was involved only in $14 \%$ of the cases. Regional lymphadenopathy was seen in $60 \%$ of the cases whereas non-regional lymphadenopathy was seen in $18 \%$ of the cases. Lymph nodes more than $1 \mathrm{~cm}$ in size in short axis diameter were only considered to be significant. Most of the patients have esophageal wall thickness $>15 \mathrm{~mm}(78 \%), 22 \%$ of the patients have esophageal wall thickness between $5-15 \mathrm{~mm}$. Distant metastases to lung and bone were seen in $2(4 \%)$ patients and $1(2 \%)$ patient respectively. Distant metastases to liver were seen in $4(8 \%)$ patients.

Figure 1 shows esophagographic findings and CT findings in a patient with liver and lung metastases.

Local invasion of the structures adjacent to the growth included Tracheo-bronchial (10\%), Aortic (8\%), Gastric (8\%), Pericardium (2\%) and Pyriform sinuses/Valeculla (2\%) invasion. The esophageal wall thickening or mass was eccentrically located in $58 \%$ of the cases with atleast minimal luminal narrowing seen in all the 50 Cases (100\%). Dilatation of the esophagus proximal to the obstructing growth was seen in 30 cases $(60 \%)$. In $70 \%$ of the patients, periesophageal soft tissue or fat stranding was seen. The cranio-caudal length of the growth were as follows: $\leq 2 \mathrm{~cm}(6 \%), 2.1-4 \mathrm{~cm}(38 \%), 4.1-6 \mathrm{~cm}(42 \%), 6.1-8$ $\mathrm{cm}(10 \%),>8 \mathrm{~cm}(4 \%)$. The most common type of growth visualized was ulcerative $(44 \%)$ followed by infiltrative $(40 \%)$. Other less common types of growth 

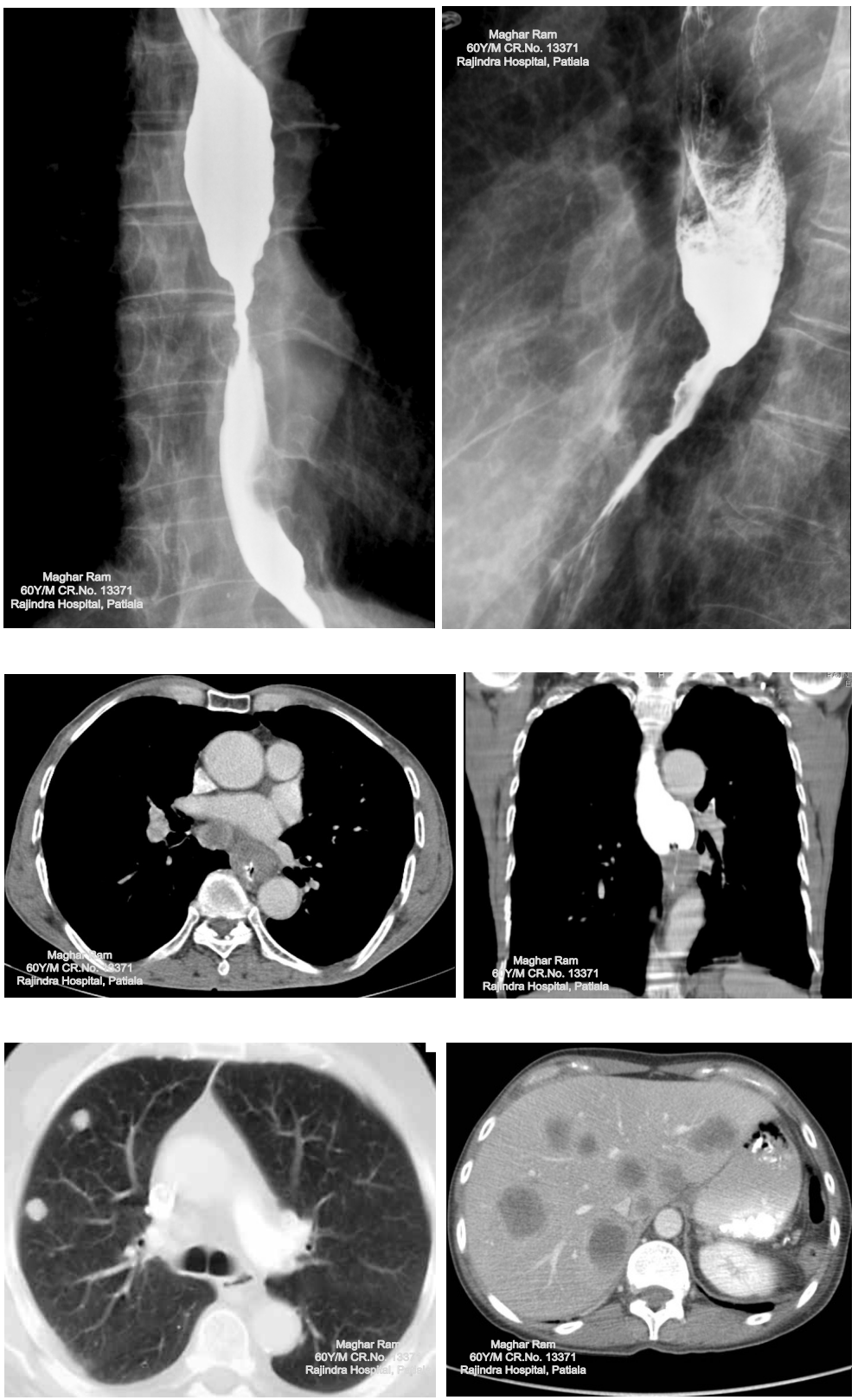

Figure 1. AP and lateral view esophagographic images showing concentric irregular abrupt luminal narrowing of mid esophagus with mucosal destruction giving Shouldering sign with hold up of contrast (HC) and dilatation of the proximal esophagus (PD). Axial and coronal CECT Thorax images showing concentric esophageal wall thickening, hold up of contrast (HC) and dilatation of proximal esophagus (PD) with maximum wall thickness of $23 \mathrm{~mm}$, involving the middle thoracic esophagus with a periesophageal lymph node (PLN) measuring $21 \mathrm{~mm}$ in SAD. Metastases to lung and liver are also shown on Pulmonary window and axial CECT image of upper abdomen respectively.

seen were polypoidal (6\%) and fungating types (10\%). Except for 1 case, the strictures seen in rest of the 49 cases (98\%) were of the irregular type (having irregular margins). Mucosal destruction/irregularity was the most common 
esophagographic finding, seen in 49 cases (98\%). Other findings includedshouldering sign seen in 38 patients (76\%) and hold up of contrast seen in proximal esophagus in $78 \%$ cases (39 patients). Figure 2 shows irregular stricture,mucosal destruction, proximal dilatation and hold of contrast in a patient with mid thoracic esophageal carcinoma alongwith corresponding CT images.The cranio-caudal lengths of the growth were as follows: $\leq 2 \mathrm{~cm}(6 \%), 2.1-4$ $\mathrm{cm}$ (42\%), 4.1 - $6 \mathrm{~cm}$ (38\%), $6.1-8 \mathrm{~cm}(10 \%),>8 \mathrm{~cm}(4 \%)$.

Table 1 describes the correlation of histopathological finding (whether squamous cell or adenocarcinoma type) with location of the carcinoma in CT findings. Similarly a correlation between histopathological finding (whether well differentiated, moderately differentiated, poorly differentiated squamous cell carcinoma or adenocarcinoma) with CT findings of local invasion or distant metastasis is illustrated in Table 2. Correlation between CT findings and esophagographic findings was found significant ( $p$ value $>0.05$ ) and Table 3 describes this correlation and significance in relation to each finding.

Table 1. Histopathological correlation with ct findings.

\begin{tabular}{cccccc}
\hline \multirow{2}{*}{ CT Findings } & \multicolumn{2}{c}{ Adenocarcinoma } & \multicolumn{2}{c}{ Squamous Cell Carcinoma } \\
\cline { 3 - 6 } & Npper & - & $\%$ age & No. & \% age \\
\hline \multirow{2}{*}{ Site Involved } & Middle & - & - & 7 & $14 \%$ \\
& Lower & 3 & - & 20 & $40 \%$ \\
\hline
\end{tabular}

All the 3 cases of Adenocarcinoma were found in the lower esophagus, none of the Adenocarcinoma was seen in upper or middle esophagus. However, Squamous cell carcinoma was seen in all the parts of esophagus-upper (14\%), middle (40\%) and lower (40\%).

Table 2. Histopathological correlation with local invasion/distant metastasis.

\begin{tabular}{ccccc}
\hline & \multicolumn{3}{c}{ Squamous Cell Carcinoma } \\
Local & Well & Moderately & Poorly & Adenocarcinoma \\
Metastasis & Differentiated & Differentiated & Differentiated & (3) \\
& $(12)$ & $(25)$ & $(10)$ & \\
\hline No. of Patients (\%) & $0(0 \%)$ & $7(28 \%)$ & $8(80 \%)$ & $2(66.6 \%)$ \\
\hline
\end{tabular}

Among the Squamous cell carcinoma, local invasion or distant metastases was most commonly seen in poorly differentiated type $(80 \%)$ followed by moderately differentiated type $(28 \%)$. No local invasion/distant metastases was seen in well differentiated type. Local invasion or distant metastases were seen in $66.6 \%$ cases of Adenocarcinoma.

Table 3. Correlation of ct findings with esophagograhic findings.

\begin{tabular}{cccccc}
\hline \multirow{2}{*}{ Findings } & \multicolumn{2}{c}{ CT Scan } & \multicolumn{2}{c}{ Esophagographic } & \multirow{2}{*}{ p value } \\
\cline { 2 - 5 } & No. & $\%$ age & No. & $\%$ age & \\
\hline Luminal Narrowing & 50 & $100 \%$ & 50 & $100 \%$ & $\mathrm{p}>0.05$ \\
Proximal Dilatation & 30 & $60 \%$ & 32 & $64 \%$ & $\mathrm{p}>0.05$ \\
\hline
\end{tabular}




\section{Continued}

\begin{tabular}{|c|c|c|c|c|c|c|}
\hline \multicolumn{2}{|c|}{ Proximal hold up of Contrast } & 36 & $72 \%$ & 39 & $78 \%$ & $\mathrm{p}>0.05$ \\
\hline \multicolumn{2}{|c|}{ Eccentric Growth } & 29 & $58 \%$ & 26 & $52 \%$ & $\mathrm{p}>0.05$ \\
\hline \multirow{3}{*}{ Site Involved } & Upper & 7 & $14 \%$ & 7 & $\mathrm{p}>0.05$ & $\mathrm{p}>0.05$ \\
\hline & Middle & 20 & $40 \%$ & 20 & $40 \%$ & $\mathrm{p}>0.05$ \\
\hline & Lower & 23 & $46 \%$ & 23 & $46 \%$ & $\mathrm{p}>0.05$ \\
\hline \multirow{5}{*}{ Length of Growth } & $\leq 2 \mathrm{~cm}$ & 3 & $6 \%$ & 3 & $6 \%$ & $\mathrm{p}>0.05$ \\
\hline & $2.1-4 \mathrm{~cm}$ & 19 & $38 \%$ & 21 & $42 \%$ & $\mathrm{p}>0.05$ \\
\hline & $4.1-6 \mathrm{~cm}$ & 21 & $42 \%$ & 19 & $38 \%$ & $\mathrm{p}>0.05$ \\
\hline & $6.1-8 \mathrm{~cm}$ & 5 & $10 \%$ & 5 & $10 \%$ & $\mathrm{p}>0.05$ \\
\hline & $>8 \mathrm{~cm}$ & 2 & $4 \%$ & 2 & $4 \%$ & $\mathrm{p}>0.05$ \\
\hline \multicolumn{2}{|c|}{ Involvement of GE Junction } & 6 & $12 \%$ & 6 & $12 \%$ & $\mathrm{p}>0.05$ \\
\hline \multicolumn{2}{|c|}{$\begin{array}{l}\text { Involvement of Pyriform } \\
\text { Sinuses/Valeculla }\end{array}$} & 1 & $2 \%$ & 1 & $2 \%$ & $\mathrm{p}>0.05$ \\
\hline
\end{tabular}

The CT findings were found to have significant correlation with the esophagographic findings ( $\mathrm{p}$ value $>$ 0.05 in each finding) in regard to luminal narrowing, proximal dilatation and hold up of contrast, eccentricity of growth, site involved, length of growth, involvement of pyriform sinuses/valeculla and involvement of GE junction.
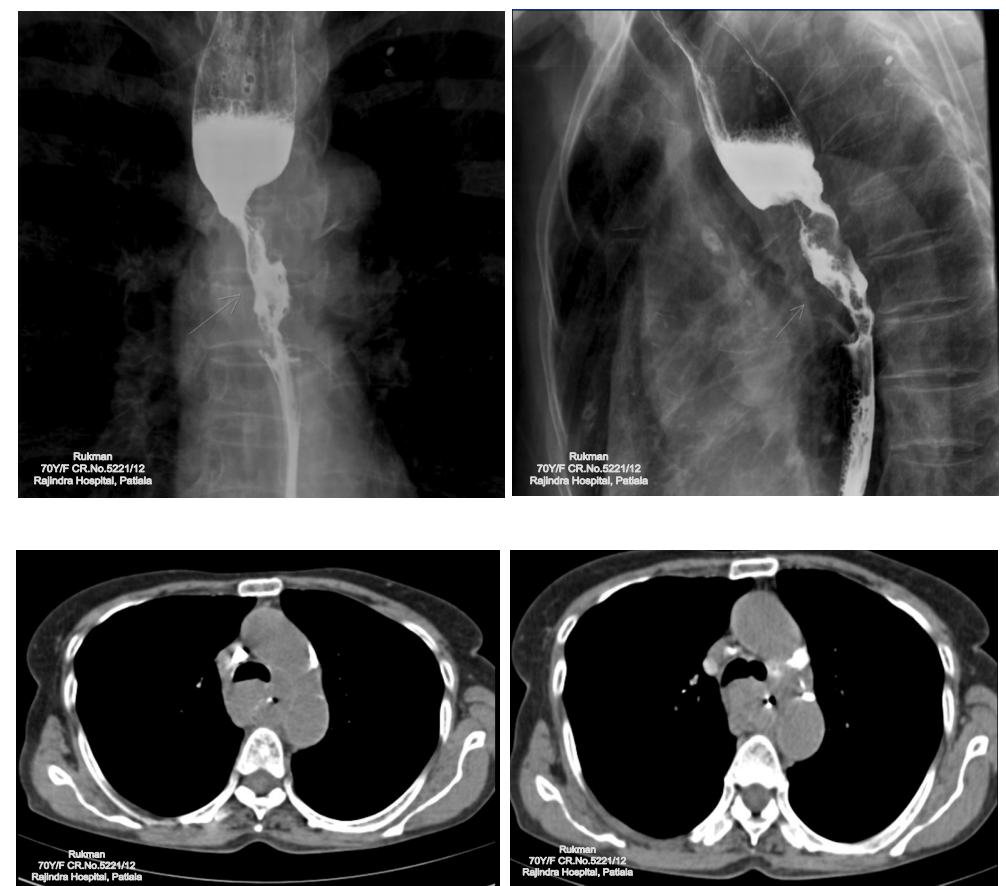

Figure 2. AP and lateral view esophagographic images showing concentric irregular abrupt luminal narrowing of midthoracic esophagus with mucosal destruction giving Shouldering sign (S) with hold up of contrast (HC) and dilatation of the proximal esophagus (PD). Axial CECT Thorax images showing concentric esophageal wall thickening (arrow), with maximum wall thickness of $23 \mathrm{~mm}$, involving the midthoracic esophagus with a periesophageal lymph node (PLN) measuring approx. $13 \mathrm{~mm}$ in SAD. 


\section{Discussion}

In this study, 29 patients (58\%) were males and 21 patients (42\%) were females, thus having a slight male predominance with a M:F ratio of 1.38:1. In a study by Mohebbi et al. [28] on 1693 patients with esophageal carcinoma in Iran, the sex ratio of $\mathrm{M}: \mathrm{F}$ in esophageal carcinoma was 1.1:1. In a study by Sinha et al. [29], the $\mathrm{M}: \mathrm{F}$ ratio in patients having carcinoma esophagus was compared between that in US $(\mathrm{M}: \mathrm{F}$ ratio $=3.5: 1)$ with that in India $(\mathrm{M}: \mathrm{F}$ ratio $=1.49: 1)$. In a study in Tamil Nadu of India by Cherian et al. [30], M:F ratio was found to be 2.16:1 in patients with esophageal carcinoma. In the study by Khan et al. [31] in valley of Kashmir, Northern India, the M:F ratio was 2.4:1. Thus, the present study correlates well with previous studies done. Most common age group of patients affected were between 55 - 65 years of age (38\%) followed by above 65 years of age $(24 \%)$ and it was found to be rare in $\leq 35$ yrs of age $(6 \%)$. In a study by Chitra et al. [32], most common age group affected was $51-60$ yrs (38\%) followed by $61-70(24 \%)$ and was found to be rare in age $<40$ yrs (5\%). In another study by Gatei et al. [33] on 40 patients of Kenyan population, the most common age group affected was 50 - 60 yrs. In a study on 1077 patients by Huang et al. [34], $50 \%$ of the cases were seen in age $40-60$ yrs and $49 \%$ of the cases were seen in age $>60$ yrs. In another study by Subhasinge et al. [35] on 48 patients, the median age of patients with esophageal carcinoma was 59.5 years. Thus, the present study correlates well with the previous studies done.

In the present study, the most common presenting symptom was dysphagia (100\%) followed by weight loss (52\%) and chest/epigastric pain (18\%). 10\% of the patients presented with cough and vomiting and $8 \%$ of the patients presented with odynophagia. $4 \%$ of the patients presented with complaint of hoarseness of voice. Only $8 \%$ of the patients presented with other complaints like GI bleed, hiccups etc. In a study by Gibbs et al. [36] on 307 patients of esophageal carcinoma symptomatic distribution was-dysphagia (83\%), weight loss (58\%), chest/abdominal pain (16\%), hoarseness of voice (2\%), nausea/vomiting (5\%). In another study by Gatei et al. [33] on 40 patients with esophageal carcinoma common symptoms included dysphagia (100\%), chest pain (45\%), cough (35\%) and vomiting (47.5\%). In another study by Subhasinge et al. [35] on 48 patients, symptomatic distribution was-progressive dysphagia (100\%), weight loss $(83.3 \%)$, chest/abdominal pain $(20.8 \%)$, odynophagia $(6.2 \%)$, regurgitation (29.2\%), abdominal discomfort/dyspepsia (6\%). Thus, the present study correlates well with the previous studies done.

The most common histological type was Squamous cell carcinoma (94\%) followed by Adenocarcinoma (6\%). In a study by Cherian et al. [30] on 994 south Indian carcinoma esophagus patients, Squamous cell carcinoma and Adenocarcinoma were seen in $92 \%$ and $8 \%$ of the cases respectively. In another study by Gatei et al. [33], 94.5\% were of the Squamous cell type. In a study by Wakhisi et al. [37] on 468 patients, Squamous cell carcinoma accounted for $90 \%$ of the cases. In another study by Nishimaki et al. [38] on 224 cases of carcinoma esopha- 
gus, $96.4 \%$ cases were of Squamous cell type. Thus, the present study correlates well with previous studies.

The lower $1 / 3^{\text {rd }}$ of the esophagus including the GE junction was the most common site (46\%) followed by middle esophagus $(40 \%)$. The upper $1 / 3^{\text {rd }}$ of esophagus was involved in $14 \%$ of cases. In a study by Wakhisi et al. [37] on 80 patients with esophageal carcinoma, site distribution was-lower esophagus 32 cases (40\%), middle esophagus 31 cases (38.8\%), and upper esophagus 17 cases (21.2\%). In a study by Cherian et al. [30], among the $4^{\text {th }}$ cohort of 242 south Indian patients with esophageal carcinoma during 2001-2004, 12.8\%, 35.1\% and $52.1 \%$ cases were seen in upper, middle and lower esophagus respectively. In a study by Pedram et al. [39] on 166 patients with esophageal carcinoma, 7.2\%, $38.6 \%$ and $54.2 \%$ cases were seen in upper, middle and lower (including cardia) esophagus. In another study by Subhasinge et al. [35] on 48 patients, $2.08 \%$, $37.5 \%, 50 \%$ of the cases were seen in upper, middle and lower esophagus respectively and $10.42 \%$ of the cases were seen involving both the middle and lower esophagus. Thus, the present study correlates well with the previous studies done.

In the present study, regional lymphadenopathy was seen in $60 \%$ of the cases whereas non-regional lymphadenopathy was seen in $18 \%$ cases. Lymph nodes more than $1 \mathrm{~cm}$ in size in short axis diameter were only considered to be significant. In a study by Nishimaki et al. [38] on 224 patients with esophageal carcinoma, $65.2 \%$ cases had regional lymph node involvement and $7.2 \%$ had non-regional lymph node metastases. In a study by Kim et al. [40], 13 out of 50 (26\%) patients had non-regional lymph node metastases. In a study by Hsu et al. [41] on 45 patients with esophageal carcinoma, regional lymph node involvement was seen in $46.7 \%$ cases and non-regional lymph node metastases was seen in $24.4 \%$ cases. Thus, the present study correlates well with the previous studies done. In the present study, most of the patients have esophageal wall thickness $>$ $15 \mathrm{~mm}$ (78\%), 22\% of the patients have wall thickness between $5-15 \mathrm{~mm}$. In a study by Roedl et al. [42] on 36 patients with early malignant esophageal lesions, $52.8 \%$ cases had esophageal wall thickness between $15-30 \mathrm{~mm}, 22.2 \%$ have thickness $>30 \mathrm{~mm}$, and $25 \%$ have thickness $<15 \mathrm{~mm}$. Thus, the present study correlates well with the previous study done.

In the present study, distant metastases seen were as follows -Liver (8\%), Lung (4\%), and bone (2\%). No metastases were seen in any other viscera (kidney, adrenals, pericardium, pleura, brain, spleen, pancreas etc.). In a study by Turkyilmaz et al. [43] on patients with esophageal carcinoma, distant metastases were as follows-Liver (7.6\%), Lung (6.6\%), Bone (1.6\%), Pancreas (1.3\%), Pleural (0.63\%). In the study by Heeren et al. [44] on 74 patients with esophageal carcinoma, distant metastases were seen in Liver (6.7\%), Lung (4.0\%) and Peritoneum (6.7\%). In a study by Quint et al. [45] on 838 patients with esophageal carcinoma, the distribution of distant metastases were-Liver (4.6\%), Lungs (2.6\%), Bone (1.2\%), Adrenals (0.66\%), Brain and Peritoneum (0.26\% each). In another 
study by Yoon et al. [46] on 81 patients with esophageal carcinoma, distant metastases were seen as-Liver (4.4\%), Lungs (2.2\%), Adrenals (1.47\%), kidney and bone $(0.73 \%$ each). Thus, the present study correlates well with the previous studies done.

Local invasion of the structures adjacent to the growth included tracheo-bronchial (10\%), aortic (8\%), gastric (8\%), pericardium $(2 \%)$ and pyriform sinuses/valeculla (2\%) invasion. In a study by Van Overhagen et al. [47] on 71 patients with esophageal carcinoma, tracheo-bronchial invasion on CT was seen in $7 \%$ of the cases and Aortic invasion in $1.4 \%$ of the cases. In a study by Daffner et al. [27] on 30 patients with esophageal carcinoma, aortic invasion was seen in $17 \%$ of the cases and tracheal invasion in $13 \%$ of the cases. Thus, the present study correlates well with the previous studies done.

The esophageal wall thickening or mass was eccentrically located in $58 \%$ of cases with at least minimal luminal narrowing seen in all the 50 Cases (100\%). Dilatation of the esophagus proximal to the obstructing growth were seen in 30 cases $(60 \%)$. In $70 \%$ of the patients, periesophageal soft tissue or fat stranding was seen. In the present study, on CT scan the length of the growth were as follows: $\leq 2 \mathrm{~cm}(6 \%), 2.1-4 \mathrm{~cm}(38 \%), 4.1-6 \mathrm{~cm}$ (42\%), $6.1-8 \mathrm{~cm}(10 \%),>8 \mathrm{~cm}$ (4\%). In a study by Roedl et al. [42] on 36 patients with early malignant esophageal lesions, $55.6 \%$ lesions were eccentric and $44.4 \%$ lesions were concentric. In the study by Huang et al. [34] on 1077 patients with thoracic esophageal carcinoma, the length of the tumor were as follows: $\leq 2 \mathrm{~cm}(9.9 \%), 2.1-4 \mathrm{~cm}(45.2 \%)$, $4.1-6 \mathrm{~cm}(32.4 \%), 6.1-8 \mathrm{~cm}(9.7 \%),>8 \mathrm{~cm}(2.8 \%)$. In another study by Yendamuri et al. [48] on 209 patients with esophageal carcinoma, tumor length was $\leq 3 \mathrm{~cm}$ in $57.9 \%$ and $>3 \mathrm{~cm}$ in $42.1 \%$ of the cases.

In the present study, the most common type of growth visualized was ulcerative $(44 \%)$ and followed by infiltrative type $(40 \%)$. Other less common types of growth seen were polypoidal type (6\%) and fungating type (10\%). In a study by Su et al. [49] on 9650 patients with esophageal carcinoma, the main gross types of esophageal carcinoma were ulcerative type (41.5\%), medullary/infiltrative type (39.6\%), fungating type (9.4\%), and scirrhous type (9.6\%). In a study by Huang et al. [6] on 1077 patients with esophageal carcinoma, the gross types of growth were-ulcerative (51.5\%), medullary/infiltrative $(41.2 \%)$, fungating (4.4\%), and others (2.9\%). In another study by Kuwano et al. [50] on 378 patients with esophageal carcinoma, gross pattern were-superficial type $(40.1 \%)$, protruding type $(10.2 \%)$, ulcerative type (12.6\%), both ulcerative and infiltrative type $(34.6 \%)$, and others $(2.4 \%)$. Thus, the present study correlates well with the previous studies done.

Except for 1 case, the strictures seen in rest of the 49 cases (98\%) were of the irregular type (having irregular margins). In esophagography, mucosal destruction/irregularity was the most common esophagographic finding, seen in 49 cases (98\%). Other findings included -Shouldering sign seen in 38 patients (76\%) and hold up of contrast was seen in proximal esophagus in 39 patients 
(78\%). The cranio-caudal length of the growth were as follows: $\leq 2 \mathrm{~cm}(6 \%), 2.1-$ $4 \mathrm{~cm}(42 \%), 4.1-6 \mathrm{~cm}$ (38\%), $6.1-8 \mathrm{~cm}(10 \%),>8 \mathrm{~cm} \mathrm{(4 \% ).}$

In the present study, on CT scan, all the 3 cases of Adenocarcinoma were found in the lower esophagus, none of the Adenocarcinoma was seen in upper or middle esophagus. However, Squamous cell carcinoma was seen in all the parts of esophagus-upper (14\%), middle (40\%) and lower (40\%). Among the Squamous cell carcinoma, local invasion or distant metastases was most commonly seen in poorly differentiated type $(80 \%)$ followed by moderately differentiated type (28\%). No local invasion/distant metastases was seen in well differentiated type. Local invasion or distant metastases were seen in $66.6 \%$ of the cases of Adenocarcinoma. The CT findings were found to have significant correlation with the esophagographic findings ( $\mathrm{p}$ value $>0.05$ in each finding) with regard to luminal narrowing, proximal dilatation and hold up of contrast, eccentricity of growth, site involved, length of growth, involvement of pyriform sinuses/valeculla and involvement of GE junction.

\section{Conclusions}

CT plays a significant role in the evaluation of patients with esophageal carcinoma by providing important information to determine which patients with esophageal carcinoma may be suitable for surgical resection. CT study primarily helps to rule out unresectable or distant metastatic disease.

CT provided significant and valuable information regarding the esophageal wall thickness, site involved, eccentricity of the growth, the approximate length of the tumor, dilatation of the esophagus just proximal to the growth, esophageal luminal narrowing, peri-esophageal soft tissue or fat stranding, local invasion to Aorta, pericardium, tracheo-bronchial tree, pyriform sinuses/valeculla, and stomach. CT also provided detailed information about the significant lymphadenopathy pattern in patients with esophageal carcinoma including both the regional and the non-regional lymphadenopathy. The site of the primary tumours (upper, middle or lower third)were also considered in determining whether the significant lymph nodes were regional or non-regional. CT also guided in determining metastases to distant organs including Liver, Lungs, Bone, Adrenals, Kidneys, Spleen, Pancreas, Brain etc.

Esophagographic (Barium Swallow) findings strongly correlated with the CT findings including esophageal luminal narrowing, hold up of contrast and dilatation of the esophagus just proximal to the growth, eccentricity of the growth, site involved, length of the growth, involvement of GE junction and involvement of pyriform sinuses/valeculla. Other significant findings in esophagography included Shouldering sign, mucosal destruction/irregularity, gross type of growth (ulcerative, fungating, polypoidal, infiltrative), type of stricture (smooth or irregular). However, Barium studies cannot provide any information regarding local invasion into mediastinal structures, regional or non-regional lymphadenopathy or metastases to distant organs which are significant for determining 
the treatment modality. CT has an advantage over esophagography for these information.

All the cases of Adenocarcinoma were seen in lower $1 / 3^{\text {rd }}$ of esophagus. Squamous cell carcinoma was seen more commonly in middle and lower esophagus than upper esophagus. The degree of differentiation of Squamous cell carcinoma also showed significant correlation with the local invasion or distant metastases. These findings strongly suggest that there exists a significant correlation between CT findings and histopathology.

\section{References}

[1] Rankin, S. (1998) Oesophageal Cancer. In: Husband, J.E.S. and Reznek, R.H., Eds., Imaging in Oncology, Isis Medical Media N, Oxford, 93-110.

[2] Daly, J.M., Fry, W.A., Little, A.G., Winchester, D.P., McKee, R.F., Stewart, A.K., et al. (2000) Esophageal Cancer: Results of an American College of Surgeons Patient Care Evaluation Study. Journal of the American College of Surgeons, 190, 562-572. https://doi.org/10.1016/S1072-7515(00)00238-6

[3] Eloubeidi, M.A., Wallace, M.B., Reed, C.E., Hadzijahic, N., Lewin, D.N., Van Velse, A., et al. (2001) The Utility of EUS and EUS Guided Fine Needle Aspiration in Detecting Celiac Lymph Node Metastasis in Patients with Esophageal Cancer: A Single Center Experience. Gastrointestinal Endoscopy, 54, 714-719. https://doi.org/10.1067/mge.2001.119873

[4] Dorfman, R.E., Alpern, M.B., Gross, B.H. and Sandler, M.A. (1991) Upper Abdominal Lymph Nodes: Criteria for Normal Size Determined with CT. Radiology, 180, 319-322. https://doi.org/10.1148/radiology.180.2.2068292

[5] Fultz, P.J., Feins, R.H., Strang, J.G., Wandtke, J.C., Johnstone, D.W., Watson, T.J., et al. (2002) Detection and Diagnosis of Nonpalpable Supraclavicular Lymph Nodes in Lung Cancer at CT and US. Radiology, 222, 245-251. https://doi.org/10.1148/radiol.2221010431

[6] Greene, F., Fritz, A. and Balch, C. (2002) Esophagus. In: Greene, F., Fritz, A. and Balch, C., Eds., AJCC Cancer Staging Handbook Part III: Digestive System 9-Esophagus, Springer-Verlag, New York, 6th Edition, 91-98.

[7] Kuszyk, B.S., Bluemke, D.A., Urban, B.A., Choti, M.A., Hruban, R.H., Sitzmann, J.V., et al. (1996) Portal Phase Contrast-Enhanced Helical CT for the Detection of Malignant Hepatic Tumors: Sensitivity Based on Comparison with Intraoperative and Pathologic Findings. AJR. American Journal of Roentgenology, 166, 91-95. https://doi.org/10.2214/ajr.166.1.8571914

[8] Levine, M.S., Chu, P., Furth, E.E., Rubesin, S.E., Laufer, I. and Herlinger, H. (1997) Carcinoma of the Esophagus and Esophagogastric Junction: Sensitivity of Radiographic Diagnosis. AJR. American Journal of Roentgenology, 168, 1423-1426. https://doi.org/10.2214/ajr.168.6.9168701

[9] Gupta, S., Levine, M.S., Rubesin, R.E., Katzka, D.A. and Laufer, I. (2003) Usefulness of Barium Studies for Differentiating Benign and Malignant Strictures of the Esophagus. AJR. American Journal of Roentgenology, 180, 737-744. https://doi.org/10.2214/ajr.180.3.1800737

[10] Levine, M.S. (1997) Esophageal Cancer Radiologic Diagnosis. Radiologic Clinics of North America, 35, 265-279.

[11] Ueyema, T., Kawamoto, K., Yamada, Y. and Masuda, K. (1998) Early Esophageal 
Carcinoma. Evaluation of the Depth of Invasion Based on Double Contrast Esophagography. Acta Radiologica, 39, 133-137. https://doi.org/10.1080/02841859809172166

[12] Kato, H., Momma, K. and Yoshida, M. (2003) Early Esophageal Cancer: Radiologic Estimation of Invasion into the Muscularis Mucosae. Abdominal Imaging, 28, 464-469. https://doi.org/10.1007/s00261-002-0074-7

[13] Glickman II, J.N. (2003) Pathology and Pathologic Staging of Esophageal Cancer. Seminars in Thoracic and Cardiovascular Surgery, 15, 167-179. https://doi.org/10.1016/S1043-0679(03)70025-2

[14] Postlethwait, R.W. (1983) Carcinoma of the Thoracic Esophagus. Surgical Clinics of North America, 63, 933-940. https://doi.org/10.1016/S0039-6109(16)43094-X

[15] Little, A.G., Ferguson, M.K., DeMeester, T.R., Hoffman, P.C. and Skinner, D.B. (1984) Esophageal Carcinoma with Respiratory Tract Fistula. Cancer, 53, 1322-1328.

https://doi.org/10.1002/1097-0142(19840315)53:6<1322::AID-CNCR2820530617>3. $0 . \mathrm{CO} ; 2-\mathrm{H}$

[16] Mandard, A.M., Chasle, J., Marnay, J., Villedieu, B., Bianco, C., Roussel, A., et al. (1981) Autopsy Findings in 111 Cases of Esophageal Cancer. Cancer, 48, 329-335. https://doi.org/10.1002/1097-0142(19810715)48:2<329::AID-CNCR2820480219>3.0 .CO;2-V

[17] Quint, L.E., Glazer, G.M., Orringer, M.B. and Gross, B.H. (1985) Esophageal Carcinoma: CT Findings. Radiology, 155, 171-175.

https://doi.org/10.1148/radiology.155.1.3975398

[18] Saunders, H.S., Wolfman, N.T. and Ott, D.J. (1997) Esophageal Cancer Radiologic Staging. Radiologic Clinics of North America, 35, 281-294.

[19] Rapp-Bernhardt, U., Welte, T., Budinger, M. and Bernhardt, T.M. (1998) Comparison of Three Dimensional Virtual Endoscopy with Bronchoscopy in Patients with Oesophageal Carcinoma Infiltrating the Tracheobronchial Tree. The British Journal of Radiology, 71, 1271-1278. https://doi.org/10.1259/bjr.71.852.10319000

[20] Picus, D., Balfe, D.M., Koehler, R.E., Roper, C.L. and Owen, J.W. (1983) CT in the Staging of Esophageal Carcinoma. Radiology, 146, 433-438.

https://doi.org/10.1148/radiology.146.2.6849089

[21] Takashima, S., Takeuchi, N., Shiozaki, H., Kobayashi, K., Morimoto, S., Ikezoe, J., et al. (1991) Carcinoma of the Esophagus: CT vs. MR Imaging in Determining Resectability. AJR, 156, 297-302. https://doi.org/10.2214/ajr.156.2.1898802

[22] Noh, H.M., Fishman, E.K., Forastiere, A.A., Bliss, D.F. and Calhoun, P.S. (1995) CT of the Esophagus: Spectrum of Disease with Emphasis on Esophageal Carcinoma. RadioGraphics, 15, 1113-1134. https://doi.org/10.1148/radiographics.15.5.7501854

[23] Desai, R.K., Tagliabue, J.R., Wegryn, S.A. and Einstein, D.M. (1991) CT Evaluation of Wall Thickening in the Alimentary Tract. RadioGraphics, 11, 771-783. https://doi.org/10.1148/radiographics.11.5.1947313

[24] Berger, A.C. and Scott, W.J. (2004) Noninvasive Staging of Esophageal Carcinoma. Journal of Surgical Research, 117, 127-133. https://doi.org/10.1016/j.jss.2003.12.023

[25] Rice, T.W. (2000) Clinical Staging of Esophageal Carcinoma. CT, EUS, and PET. Chest Surgery Clinics of North America, 10, 471-485.

[26] Halvorsen, R.A., Magruder-Habib, K., Foster, W.L., Roberts, L., Postlethwait, R.W. and Thompson, W.M. (1986) Esophageal Cancer Staging by CT: Long-Term Follow-Up Study. Radiology, 161, 147-151. 
https://doi.org/10.1148/radiology.161.1.3763857

[27] Daffner, R.H., Halber, M.D., Postlethwait, R.W., Korobkin, M. and Thompson, W.M. (1979) CT of the Esophagus. II. Carcinoma. American Journal of Roentgenology, 133, 1051-1055. https://doi.org/10.2214/ajr.133.6.1051

[28] Mohebbi, M., Wolfe, R., Jolley, D., Forbes, A.B., Mahmoodi, M. and Burton, R.C. (2011) The Spatial Distribution of Esophageal and Gastric Cancer in Caspian Region of Iran: An Ecological Analysis of Diet and Socio-Economic Influences. International Journal of Health Geographics, 10, 13. https://doi.org/10.1186/1476-072X-10-13

[29] Sinha, R., Anderson, D.E., McDonald, S.S. and Greenwald, P. (2003) Cancer Risk and Diet in India. Journal of Postgraduate Medicine, 49, 222-228.

[30] Cherian, J.V., Sivaraman, R., Muthusamy, A.K. and Jayanthi, V. (2007) Carcinoma of the Esophagus in Tamil Nadu (South India): 16-Year Trend from a Tertiary Center. Journal of Gastrointestinal and Liver Diseases, 16, 245-249.

[31] Khan, N.A., Teli, M.A., Mohib-Ul Haq, M., Bhat, G.M., Lone, M.M. and Afroz, F. (2011) A Survey of Risk Factors in Carcinoma Esophagus in the Valley of Kashmir, Northern India. Journal of Cancer Research and Therapeutics, 7, 15-18. https://doi.org/10.4103/0973-1482.80431

[32] Chitra, S., Ashok, L., Anand, L., Srinivasan, V. and Jayanthi, V. (2004) Risk Factors for Esophageal Cancer in Coimbatore, Southern India: A Hospital-Based Case-Control Study. Indian Journal of Gastroenterology, 23, 117-118.

[33] Gatei, D.G., Odhiambo, P.A., Orinda, D.A.O., Muruka, F.J. and Wasunna, A. (1978) Retrospective Study of Carcinoma of the Esophagus in Kenya. Cancer Research, 38, 303-307.

[34] Huang, W., Li, B., Gong, H., Yu, J., Sun, H. and Zhou, T. (2010) Pattern of Lymph Node Metastases and Its Implication in Radiotherapeutic Clinical Target Volume in Patients with Thoracic Esophageal Squamous Cell Carcinoma: A Report of 1077 Cases. Radiotherapy and Oncology, 95, 229-233.

https://doi.org/10.1016/j.radonc.2010.01.006

[35] Subasinghe, D. and Samarasekera, D.N. (2010) Delay in the Diagnosis of Esophageal Carcinoma: Experience of a Single Unit from a Developing Country. Indian Journal of Cancer, 47, 151-155. https://doi.org/10.4103/0019-509X.63009

[36] Gibbs, J.F., Rajput, A., Chadha, K.S., Douglas, W.G., Hill, H., Nwogu, C., et al. (2007) The Changing Profile of Esophageal Cancer Presentation and Its Implication for Diagnosis. Journal of the National Medical Association, 99, 620-626.

[37] Wakhisi, J., Patel, K., Buziba, N. and Rotich, J. (2005) Oesophageal Cancer in North Rift Valley of Western Kenya. African Health Sciences, 5, 157-163.

[38] Nishimaki, T., Tanakt, O., Ando, N., Ide, H., Watanabe, H. and Shinoda, M. (1999) Evaluation of the Accuracy of Preoperative Staging in Thoracic Esophageal Cancer. The Annals of Thoracic Surgery, 68, 2059-2064. https://doi.org/10.1016/S0003-4975(99)01171-6

[39] Pedram, A., Mahmodlou, R., Enshayi, A. and Sepehrvand, N. (2011) Esophageal Cancer in Northwestern Iran. Indian Journal of Cancer, 48, 165-169. https://doi.org/10.4103/0019-509X.82875

[40] Kim, K., Park, S.J., Kim, B.T., Lee, K.S. and Shim, Y.M. (2001) Evaluation of Lymph Node Metastases in Squamous Cell Carcinoma of the Esophagus with Positron Emission Tomography. The Annals of Thoracic Surgery, 71, 290-294. https://doi.org/10.1016/S0003-4975(00)02221-9 
[41] Hsu, W.H., Hsu, P.K., Wang, S.J., Lin, K.H., Huang, C.S., Hsieh, C.C., et al. (2009) Positron Emission Tomography-Computed Tomography in Predicting Locoregional Invasion in Esophageal Squamous Cell Carcinoma. The Annals of Thoracic Surgery, 87, 1564-1568. https://doi.org/10.1016/j.athoracsur.2009.02.065

[42] Roedl, J.B., Colen, R.R., King, K., Fischman, A.J., Mueller, P.R. and Blake, M.A. (2008) Visual PET/CT Scoring for Nonspecific 18F-FDG Uptake in the Differentiation of Early Malignant and Benign Esophageal Lesions. American Journal of Roentgenology, 191, 515-521. https://doi.org/10.2214/AJR.07.3320

[43] Turkyilmaz, A., Eroglu, A., Aydın, Y., Yılmaz, Ö. and Karaoğlanoğlu, N. (2009) Survival in Esophageal Cancer Patients with Hematogenous Distant Organ Metastases. Turkish Journal of Medical Sciences, 39, 415-421.

[44] Heeren, P.A., Jager, P.L., Bongaerts, F., Van Dullemen, H., Sluiter, W. and Plukker, J.T. (2004) Detection of Distant Metastases in Esophageal Cancer with 18F-FDG PET. Journal of Nuclear Medicine, 45, 980-987.

[45] Quint, L.E., Hepburn, L.M., Francis, I.R., Whyte, R.I. and Orringer, M.B. (1995) Incidence and Distribution of Distant Metastases from Newly Diagnosed Esophageal Carcinoma. Cancer, 76, 1120-1125.

https://doi.org/10.1002/1097-0142(19951001)76:7<1120::AID-CNCR2820760704>3. $\underline{0 . \mathrm{CO} ; 2-\mathrm{W}}$

[46] Yoon, Y.C., Lee, K.S., Shim, Y.M., Kim, B.T., Kim, K. and Kim, T.S. (2003) Metastasis to Regional Lymph Nodes in Patients with Esophageal Squamous Cell Carcinoma: CT versus FDG PET for Presurgical Detection-Prospective Study. Radiology, 227, 764-770. https://doi.org/10.1148/radiol.2281020423

[47] van Overhagen, H., Laméris, J.S., Berger, M.Y., Klooswijk, A.I., Tilanus, H.W. and van Pel, R. (1993) CT Assessment of Resectability Prior to Transhiatal Oesophagectomy or Oesophageal/Gastro-Oesophageal Junction Carcinoma. Journal of Computer Assisted Tomography, 17, 367-373. https://doi.org/10.1097/00004728-199305000-00005

[48] Yendamuri, S., Swisher, S.G., Correa, A.M., Hofstetter, W., Ajani, J.A., Francis, A., et al. (2009) Esophageal Tumor Length Is Independently Associated with Long-Term Survival. Cancer, 115, 508-516. https://doi.org/10.1002/cncr.24062

[49] Su, M., Li, X.Y., Tian, D.P., Wu, M.Y., Wu, X.Y., Lu, S.M., et al. (2004) Clinicopathologic Analysis of Esophageal and Cardiac Cancers and Survey of Molecular Expression on Tissue Arrays in Chaoshan Littoral of China World. Journal of Gastroenterology, 10, 2163-2167. https://doi.org/10.3748/wjg.v10.i15.2163

[50] Kuwano, H., Nakajima, M., Miyazaki, T. and Kato, H. (2003) Distinctive Clinicopathological Characteristics in Esophageal Squamous Cell Carcinoma. Annals of Thoracic and Cardiovascular Surgery, 9, 6-13. 